\title{
Caffeine in bronchiolitis associated apnea: A retrospective cohort study
}

\author{
Mark Duffett ${ }^{\mathrm{a}, *}$, Daisy M. Liu ${ }^{\mathrm{b}}$, Ashish Deshpande ${ }^{\mathrm{a}}$ and Karen Choong ${ }^{\mathrm{a}}$ \\ ${ }^{a}$ Department of Pediatrics, McMaster University, Hamilton, ON, Canada \\ ${ }^{\mathrm{b}}$ Schulich School of Medicine and Dentistry, University of Western Ontario, London, ON, Canada
}

Received 27 July 2010

Revised 18 January 2011

Accepted 6 February 2011

\begin{abstract}
Young infants with bronchiolitis commonly present with apnea. Caffeine is effective in treating apnea of prematurity and has been used to treat apnea associated with bronchiolitis.

To evaluate whether caffeine administration to infants presenting with apnea in the setting of bronchiolitis was associated with a decreased rate of endotracheal intubation and mechanical ventilation, compared to infants who did not receive caffeine. Retrospective cohort study.

University affiliated tertiary care children's hospital. Twenty-eight infants less than 3 months of age, 13 of whom received caffeine. Fewer infants who received caffeine required endotracheal intubation and invasive mechanical ventilation $(\mathrm{OR}=0.30$ $95 \%$ CI 0.07 to $1.4, p=0.15$ ), but this was not statistically significant. Infants who received caffeine were more likely to be treated with non-invasive ventilation than infants in the control group $(\mathrm{OR}=14$; $95 \%$ CI 2.1 to $98 p=0.01)$. Only one patient who was initially managed with non-invasive ventilation was subsequently intubated. There was no difference in the duration of total respiratory support, duration of invasive mechanical ventilation, hospital and pediatric critical care unit stay. All infants survived. This study does not provide adequate evidence to support or refute the routine use of caffeine in bronchiolitis associated apnea.
\end{abstract}

Keywords: Bronchiolitis, apnea, caffeine, respiratory syncytial virus, mechanical ventilation, critical care

\section{Introduction}

Acute viral bronchiolitis is one of the most common causes of respiratory disease in young children, and is responsible for 17 to 31 hospitalizations per 1000 person-years among children less than one year of age $[1,2]$. Ten to $15 \%$ of those who are hospitalized require admission to a pediatric intensive care unit for progressive respiratory failure, sepsis or apnea [3]. As many as $25 \%$ of these infants present with apnea [4]. Age less than one month is the primary independent

*Corresponding author: Dr. Mark Duffett, McMaster Children's Hospital, MUMC 1E1A 1200 Main St West, Hamilton, Ontario L8S 4J9, Canada. Tel.: +1 9055215008 x75216; Fax: +1 905521 5008; E-mail: duffetmc@mcmaster.ca. risk factor for bronchiolitis associated apnea [5]. The presence of apnea increases the relative risk for mechanical ventilation by more than six fold in children with bronchiolitis [4]. Suggested pathophysiologic mechanisms for bronchiolitis associated apnea include airway obstruction due to secretions, altered laryngeal chemoreceptor sensitivity, a direct effect of respiratory syncytial virus, and increased severity of illness and resultant hypoxemia [6-9].

Current management of apnea is primarily supportive and hence the role of respiratory stimulants such as caffeine and other methylxanthines in the setting of bronchiolitis has been explored. It has been suggested that caffeine may be a safe adjunctive treatment modality for these infants, particularly in centres that do not have pediatric intensive care unit support. 
Caffeine is effective in reducing the severity and need for mechanical ventilation in apnea of prematurity [10]. It has also been shown to reduce the episodes of desaturation in infants with postanesthetic apnea [11]. Current published data on the use of methylxanthines to treat bronchiolitis associated apnea is limited to four case reports totaling 13 infants (ten of whom received caffeine, two aminophylline and one theophylline) [12-15]. These reports suggest that caffeine may reduce the severity of apnea in this setting; all infants successfully avoided intubation. We found no comparative observational studies or clinical trials of caffeine use in this population. The objective of this retrospective cohort study was to evaluate whether caffeine administration to infants presenting with apnea in the setting of bronchiolitis was associated with a decreased rate of endotracheal intubation and mechanical ventilation, compared to infants who did not receive caffeine.

\section{Methods}

\subsection{Study design and patient selection}

Infants three months or less corrected age, who were admitted to McMaster Children's Hospital between January 2003 and April 2007, with a diagnosis of bronchiolitis and clinically significant episodes of apnea, were eligible for inclusion into this study. Patients were identified through the hospital's health records and Pediatric Critical Care Unit (PCCU) databases. Clinically significant apnea was defined as apnea requiring intervention such as physical stimulation, oxygen therapy, positive pressure ventilation or consultation with the Pediatric Critical Care service. We excluded infants if apnea was attributed to causes other than bronchiolitis, and patients who received caffeine within five days prior to admission. Two reviewers applied the eligibility criteria and extracted data for included infants using a standardized case report form. Within this cohort, infants who received caffeine were compared to controls that did not. This study was approved by the Hamilton Health Sciences/ McMaster University Faculty of Health Sciences Research Ethics Board. The primary outcome was the rate of endotracheal intubation and mechanical ventilation. Secondary outcomes included the length of PCCU, length of hospital stay, duration of mechanical ventilation, and the total duration of respiratory support. We defined respiratory support as the need for either invasive, non-invasive ventilation (NIV), or oxygen therapy.

\subsection{Statistical methods}

We used SPSS, version 13.0 (SPSS, Chicago, IL) to perform the statistical analyses. For comparing outcomes, we used the Fisher's exact test for categorical variables and Mann-Whitney $U$ tests for continuous variables. All tests were two-sided and we considered $p$ values of $\leq 0.05$ to be statistically significant.

\section{Results}

We included all twenty-eight infants who fulfilled all eligibility criteria, 13 of whom received caffeine. As shown in Table 1, the baseline characteristics of these two groups were similar. Eight of the 13 infants received a single dose of caffeine (median $10 \mathrm{mg} / \mathrm{kg}$, range 6.7 to $11.4 \mathrm{mg} / \mathrm{kg}$ ). The remaining five infants received a median maintenance dose of $2.5 \mathrm{mg} / \mathrm{kg}$ (range 1.9 to $3.4 \mathrm{mg} / \mathrm{kg}$ ) once daily for a median of three days (range two to eight days). As shown in Table 2 fewer infants in the caffeine group required endotracheal intubation and invasive mechanical ventilation $(\mathrm{OR}=0.3095 \% \mathrm{CI} 0.07$ to $1.4, p=0.15)$, but this was not statistically significant. Infants who received caffeine were more likely to be treated with non-invasive ventilation than infants in the control group $(\mathrm{OR}=14 ; 95 \%$ CI 2.1 to $98, p=0.01)$. Only one patient (in the caffeine group) who was initially managed with NIV was subsequently intubated. There was no statistical difference in the duration of total respiratory support, duration of invasive mechanical ventilation, hospital and PCCU stay. No adverse effects were reported and all infants survived. We were unable to assess any potential effect of dose or duration of treatment on any of these outcomes because of the small number of infants in each of these subgroups.

\section{Discussion}

In this retrospective cohort study of young infants with bronchiolitis associated apnea, there was a nonsignificant trend towards a reduction in intubation and mechanical ventilation in infants who were treated with caffeine. This trend however, was offset by a significantly greater proportion of NIV use in caffeine treated infants. There are several possible explanations for this result: caffeine may have reduced the severity of apneas, enabling these infants to be managed with NIV rather than invasive ventilation. Alternatively, physician bias 
Table 1

Baseline characteristics of the bronchiolitis study population

\begin{tabular}{|c|c|c|c|}
\hline Characteristics & $\begin{array}{l}\text { Infants who received } \\
\text { caffeine }(n=13)\end{array}$ & Control $(\mathrm{n}=15)$ & $P$ \\
\hline Post-natal age (weeks) $*$ & $3.0(2-8)$ & $4.28(2-11)$ & 0.031 \\
\hline Gestational age at birth (weeks) * & $38(29-40)$ & $37(30-40)$ & 0.981 \\
\hline Admission weight $(\mathrm{kg}) *$ & $3(2.5-4.8)$ & $3.78(2.6-5.4)$ & 0.062 \\
\hline Males n $(\%)$ & $7(54)$ & $7(47)$ & 1.000 \\
\hline Preterm n $(\%)$ & $6(46)$ & $9(60)$ & 0.705 \\
\hline $\begin{array}{l}\text { Pediatric risk of mortality score III } \\
\text { on admission } * *\end{array}$ & $3(0-6)$ & $3(0-6)$ & 1.000 \\
\hline Infants with comorbidities $* * * \mathrm{n}(\%)$ & $4(31)$ & $2(13)$ & 0.639 \\
\hline Viral respiratory isolates $\mathrm{n}(\%)$ & & & 0.297 \\
\hline Respiratory syncytial virus & $7(54)$ & $12(80)$ & \\
\hline Parainfluenza & $1(7)$ & $0(0)$ & \\
\hline Bacterial respiratory isolates $\mathrm{n}(\%)$ & & & 0.206 \\
\hline Hemophilius influenza & $1(7)$ & $0(0)$ & \\
\hline Staphylococcus aureus & $1(7)$ & & \\
\hline
\end{tabular}

*Data are expressed as median (minimum-maximum).

$* *$ Pediatric risk of mortality score III (17).

$* * *$ Chronic lung disease (2), atrial septal defect (2), tetralogy of Fallot (1), ventricular septal defect (1).

Table 2

Patient outcomes of the bronchiolitis study population

\begin{tabular}{lccc}
\hline Outcome * & $\begin{array}{c}\text { Infants who received } \\
\text { caffeine (n=13) }\end{array}$ & Control (n=15) & $P$ \\
\hline Invasive mechanical ventilation n (\%) & $4(31 \%)$ & $9(60 \%)$ & 0.15 \\
Non-invasive ventilation n (\%) & $9(69 \%)$ & $2(13 \%)$ & 0.01 \\
Length of hospital stay (days) & $8(5-16)$ & $8(2-16)$ & 0.61 \\
Length of pediatric intensive care unit stay (days) & $3(1-10)$ & $7(1-15)$ & 0.12 \\
Duration of invasive mechanical ventilation (days) & $0(0-9)$ & $2.5(0-11)$ & 0.12 \\
Duration of non-invasive ventilation (days) & $0.2(0-5)$ & $0(0-5)$ & 0.01 \\
Duration of respiratory support (days) ** & $4(1-9)$ & $6(1-12)$ & 0.11 \\
\hline
\end{tabular}

*Data are expressed as median (minimum-maximum) unless otherwise indicated.

$* *$ Respiratory support $=$ total duration of oxygen therapy, invasive and/or non-invasive ventilation.

may have influenced the use of caffeine in conjunction with NIV in an attempt to avoid intubation and invasive mechanical ventilation. We also cannot exclude that changing practice patterns over the four year study period had an influence over the rate of NIV and invasive mechanical ventilation use. While it may be tempting to attribute the trend towards shorter duration of respiratory support and PCCU stay to caffeine in this group, it is unclear in this retrospective study whether this is due to the effect of caffeine or the co-intervention (NIV). Current literature suggests that NIV used for acute respiratory failure of other etiologies does not shorten length of stay when compared to invasive mechanical ventilation, but it is unclear if this can be generalized to infants presenting with apnea [16]. Such potential for bias as well as the small sample size and the limitations of extracting data retrospectively from medical records underscores the major limitations of observational studies in this setting. Nevertheless, this is the largest reported cohort of infants with bronchiolitis associated apnea treated with caffeine to date and is the first published comparative study.

This study does not provide adequate evidence to support or refute the routine use of caffeine in bronchiolitis associated apnea. An adequately powered prospective trial to evaluate the efficacy of caffeine as an adjunct to the management of this condition is required. Such a study must be large enough to control for potential confounders such as the use of NIV and assessment of the safety of caffeine in this setting. 


\section{Acknowledgments}

We would like to thank Dr. Forough Farrokhyar from the Department of Surgery \& the Department Clinical Epidemiology and Biostatistics, McMaster University for her help in the statistical analysis.

\section{References}

[1] Shay DK, Holman RC, Newman RD, Liu LL, Stout JW, Anderson LJ. Bronchiolitis-associated hospitalizations among US children, 1980-1996. JAMA 1999;282(15):1440-6.

[2] Koehoorn M, Karr CJ, Demers PA, Lencar C, Tamburic L, Brauer M. Descriptive epidemiological features of bronchiolitis in a population-based cohort. Pediatrics 2008;122(6):1196-203.

[3] Wang EE, Law BJ, Stephens D. Pediatric Investigators Collaborative Network on Infections in Canada (PICNIC) prospective study of risk factors and outcomes in patients hospitalized with respiratory syncytial viral lower respiratory tract infection. J Pediatr 1995;126(2):212-9.

[4] Kneyber MC, Brandenburg AH, de Groot R, Joosten KF, Rothbarth PH, Ott A, et al. Risk factors for respiratory syncytial virus associated apnoea. Eur J Pediatr 1998;157(4):331-5.

[5] Willwerth BM, Harper MB, Greenes DS. Identifying hospitalized infants who have bronchiolitis and are at high risk for apnea. Ann Emerg Med 2006;48(4):441-7.

[6] Tripp RA, Dakhama A, Jones LP, Barskey A, Gelfand EW, Anderson LJ. The $\mathrm{G}$ glycoprotein of respiratory syncytial virus depresses respiratory rates through the CX3C motif and substance P. J Virol 2003;77(11):6580-4.
[7] Anas N, Boettrich C, Hall CB, Brooks JG. The association of apnea and respiratory syncytial virus infection in infants. $\mathbf{J}$ Pediatr 1982;101(1):65-8.

[8] Pickens DL, Schefft G, Thach BT. Prolonged apnea associated with upper airway protective reflexes in apnea of prematurity. Am Rev Respir Dis 1988;137(1):113-8.

[9] Blum DJ, McCaffrey TV. Age-related responses of laryngeal airway resistance to peripheral and central chemoreceptor stimulation. Ann Otol Rhinol Laryngol 1984;93(5 Pt 1):488-93.

[10] Schmidt B, Roberts RS, Davis P, Doyle LW, Barrington KJ, Ohlsson A, et al. Caffeine for Apnea of Prematurity Trial Group. Caffeine therapy for apnea of prematurity. N Engl J Med 2006;354(20):2112-21.

[11] Henderson-Smart DJ, Steer P. Prophylactic caffeine to prevent postoperative apnea following general anesthesia in preterm infants. Cochrane Database Syst Rev 2001;(4):CD000048.

[12] DeBuse P, Cartwright D. Respiratory syncytial virus with apnoea treated with theophylline. Med J Aust 1979;2(6): 307-8.

[13] Johnston DM, Kuzemko JA. Virus-induced apnoea and theophylline. Lancet 1992;340(8831):1352.

[14] Sajit NT, Steggall M, Padmakumar B. Apnoeas in bronchiolitis: is there a role for caffeine? Arch Dis Child 2005;90 (4):438.

[15] Tobias JD. Caffeine in the treatment of apnea associated with respiratory syncytial virus infection in neonates and infants. South Med J 2000;93(3):294-6.

[16] Yañez LJ, Yunge M, Emilfork M, Lapadula M, Alcántara A, Fernández C, et al. A prospective, randomized, controlled trial of noninvasive ventilation in pediatric acute respiratory failure. Pediatr Crit Care Med 2008;9(5):484-9.

[17] Pollack MM, Patel KM, Ruttimann UE. The Pediatric Risk of Mortality III-Acute Physiology Score (PRISM III-APS): a method of assessing physiologic instability for pediatric intensive care unit patients. J Pediatr 1997;131(4):575-81. 